\title{
É preciso adaptar-se: uma genealogia crítica das fontes evolucionistas do neoliberalismo
}

STIEGLER, Barbara. Il faut s'adapter : sur un nouvel impératif politique. Paris: Gallimard, 2019. 336p.

\section{Elton Corbanezi* (1)}

\section{Resumo}

O objetivo do texto é apresentar o livro Il faut s'adapter : sur un nouvel impératif politique, de Barbara Stiegler. Na obra, a autora desenvolve uma genealogia crítica do neoliberalismo considerando as fontes evolucionistas que embasam o pensamento político de Walter Lippmann e de John Dewey. Desse modo, a partir da constatação de uma lacuna na genealogia do neoliberalismo apresentada por Michel Foucault em Nascimento da biopolítica, Stiegler procura mostrar as bases naturalistas que informam o debate norte-americano nos anos imediatamente anteriores à formulação teórica do neoliberalismo. O livro aborda as concepções opostas dos autores estadunidenses quanto à democracia, ao "novo liberalismo" e à ideia de atraso da espécie humana em relação à aceleração da sociedade industrial do início do século XX. Ao evidenciar o embate entre os autores, Stiegler argumenta que o pragmatismo de Dewey se apresenta como a primeira crítica política e filosófica do neoliberalismo vindouro. Analisando Il faut s'adapter também à luz do contexto em que o livro se inscreve, a resenha pretende mostrar como a obra constitui uma contribuição relevante para a pesquisa sociológica sobre o neoliberalismo, especialmente para os estudos foucaultianos sobre o tema.

Palavras-chave: neoliberalismo, adaptação, evolucionismo, Lippmann, Dewey.

* Universidade Federal de Mato Grosso, Cuiabá, MT, Brasil. 


\section{It is necessary to adapt: a critical genealogy of the evolutionist sources of neoliberalism}

\section{Abstract}

This text aims to present the book /l faut s'adapter : sur un nouvel impératif politique, by Barbara Stiegler. In the book, the author develops a critical genealogy of neoliberalism considering the evolutionary sources that underlie the political thought of Walter Lippmann and John Dewey. Thus, finding a gap in the genealogy of neoliberalism presented by Michel Foucault in The Birth of Biopolitics, Stiegler seeks to show the naturalist bases that inform the North American debate in the years immediately preceding the theoretical formulation of neoliberalism. The book covers the opposing conceptions of American authors in regarding to democracy, the "new liberalism" and the idea of the backwardness of the human species in relation to the acceleration of industrial society in the early 20th century. In contrasting the two authors, Stiegler argues that Dewey's pragmatism presents itself as the first political and philosophical criticism of the coming neoliberalism. Analyzing II faut s'adapter also in the light of the context in which the book is inscribed, the review intends to show how the work constitutes a relevant contribution to sociological research on neoliberalism, especially for Foucauldian studies on the subject.

Keywords: neoliberalism, adaptation, evolutionism, Lippmann, Dewey.

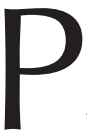

ublicado em 2019, II faut s'adapter : sur un nouvel impératif politique ("É preciso adaptar-se: sobre um novo imperativo político", em tradução livre), ${ }^{1}$ de Barbara Stiegler, apresenta uma inédita e relevante genealogia do neoliberalismo. O livro se inscreve, assim, na tradição dos estudos foucaultianos, cuja genealogia do liberalismo e do neoliberalismo remonta, respectivamente, a dois célebres cursos ministrados no Collège de France, a saber, Securité, territoire, population (1977-1978) e Naissance de la biopolitique (1978-1979), ambos publicados em 2004 também pela Editora Gallimard.

Como se sabe, a genealogia foucaultiana do neoliberalismo, abordada especialmente em Nascimento da biopolítica, volta-se sobretudo a duas

${ }^{1}$ Ainda não há tradução da obra para a língua portuguesa. Todas as traduções são de minha responsabilidade. 
perspectivas teóricas e políticas específicas: o ordoliberalismo alemão e o neoliberalismo norte-americano da Escola de Chicago. Estaria aí - bem compreendidas suas relações de ruptura e de continuidade com o liberalismo clássico - a proveniência do novo modo de governo e de organização da vida social, cuja forma, no final dos anos 1970, antes dos governos Margaret Thatcher e Ronald Reagan, era ainda bastante incipiente. No momento em que Foucault (2004b) apresentava ao público sua pesquisa, a hegemonia neoliberal - ou dos neoliberalismos - e sua racionalidade se inscreviam ainda, portanto, em um vir a ser.

Em seu livro, elaborado quase meio século após o início do processo de neoliberalização das sociedades ocidentais contemporâneas, Barbara Stiegler leva adiante o programa de pesquisa iniciado por Foucault, partindo, porém, da constatação de uma lacuna na genealogia do intelectual francês. Para a autora, Foucault não teria notado uma das proveniências do neoliberalismo, a saber, as bases evolucionistas que informam o debate norte-americano nos anos imediatamente anteriores à formulação teórica do neoliberalismo, cujos marcos históricos de fundação são, como se sabe, o Colóquio Walter Lippmann, realizado em agosto de 1938 em Paris, e, quase uma década depois, a constituição da Sociedade Mont-Pèlerin (1947), organização intelectual internacional de liberais em atividade ainda hoje. De tal lacuna, sustenta Stiegler (p. 13, 177), resultaria o equívoco de Foucault em interpretar o neoliberalismo, a partir das bases ordoliberais e norte-americanas, como fundamentalmente antinaturalista.

Com efeito, uma ruptura essencial do neoliberalismo com a doutrina econômica do liberalismo clássico reside na desconstrução da crença metafísica deste no naturalismo do laissez-faire. Uma lição inequívoca de Nascimento da biopolítica é a necessidade incontornável de artifícios estatais e jurídicos para tornar possível a sociedade de mercado. Walter Lippmann, autor homenageado no Colóquio de 1938 e objeto do livro de Barbara Stiegler, já sustentava que o intervencionismo, na refundação do liberalismo, apresentava-se como uma realidade irrefutável: o problema consistiria basicamente em definir seu grau, de modo a evitar a planificação 
e o coletivismo das experiências socialistas e keynesianas. O equívoco do liberalismo clássico teria sido apresentar de maneira descritiva o aspecto normativo da realidade social, isto é, seu objetivo em termos evolutivos, o devir necessário da ordem social, a ser, contudo, artificialmente constituída. A célebre metáfora do "código de trânsito", apresentada por Lippmann em The good society (1937) e debatida no ano seguinte no Colóquio em sua homenagem, evidencia a questão: nem liberdade total para a circulação (ingenuidade dogmática do laissez-faire), nem controle absoluto sobre a movimentação (planificação estatal), mas um código de regras a ser aperfeiçoado constantemente e a partir do qual se oriente o funcionamento da economia de mercado. Não obstante o artifício jurídico e estatal contrário às leis naturais do laissez-faire, segundo o qual o mercado funcionaria como dispositivo natural de regulação social, II faut s'adapter procura avançar na discussão ao mostrar as bases naturalistas que fundamentam o debate inicial e constitutivo da formulação teórica do neoliberalismo no contexto norte-americano entre 1910 e 1930. Mais especificamente, trata-se de analisar a apropriação diversa das teorias evolucionistas realizadas, de um lado, por Walter Lippmann, e, de outro, por John Dewey.

O objeto principal da autora, contudo, é a obra de Walter Lippmann. São mostradas as influências teóricas para a formulação do seu pensamento político (o que envolve a apropriação - sempre bastante seletiva e também crítica, assinala Stiegler em todo o livro - de uma variedade de filosofias como as de Adam Smith, Herbert Spencer, Graham Wallas, Henri Bergson, Friedrich Nietzsche, além do pragmatismo jurídico de Oliver Wendell Holmes e filosófico de William James e do próprio John Dewey); sua oposição ao modelo democrático jeffersoniano refratário à aceleração industrial, em favor dos acentos elitistas da concepção hamiltoniana de poder; sua proximidade com políticos (elaborou parte do programa de política industrial do republicano Theodore Roosevelt e participou do governo do democrata Woodrow Wilson como coordenador do escritório encarregado de formular a política externa norte-americana no pós-guerra); e seu papel como editor fundador, junto com Herbert Croly, da revista The 
New Republic. ${ }^{2}$ Desse modo, a autora mobiliza elementos da trajetória do jornalista e ensaísta norte-americano para melhor analisar suas principais obras, tais como A preface to politics (1913), Drift and mastery (1914), Public opinion (1922), The phantom public (1925) e The good society (1937). Procedendo assim, trata-se de compreender e mostrar ao leitor a démarche do pensamento político lippmanniano, fazendo sobressair também suas contradições e paradoxos como, por exemplo, sua oscilação em relação à política eugenista - recusa-a em The phantom public e a defende em The good society (Stiegler, 2019, p. 76 e nota 64, p. 301) -, bem como sua concepção de democracia por vezes ambivalente, conforme diferentes momentos de sua obra. ${ }^{3}$

Ao longo do livro, os temas abordados por Lippmann e suas posições são problematizados a partir de John Dewey, que opera, assim, como uma espécie de contraponto constante a partir do qual a autora incide sua própria crítica às bases do pensamento neoliberal nascente. Na disputa teórica e política dos autores norte-americanos, estão em jogo, basicamente, a formulação do "novo liberalismo" e suas concepções de democracia. De saída, os dois intelectuais diagnosticam a crise do liberalismo e da democracia nas sociedades industriais no contexto da Primeira Guerra Mundial (19141919) - na qual ambos defenderam a participação norte-americana, em

${ }^{2}$ Stiegler (p. 46) nomeia The New Republic como jornal (journal, em francês), em vez de revista (revue), equivalente mais próximo de magazine, como o faz Bruno Latour (2008, p. 33) na apresentação da edição francesa de The phantom public e como, de fato, o periódico estadunidense se classifica. A partir da biografia de Ronald Steel (1999) sobre Lippmann, Latour sublinha a passagem do jornalista norte-americano também pelos jornais World e, depois, Herald Tribune, o qual, não obstante sua linha editorial conservadora, divergente da visão liberal progressista de Lippmann, conferia liberdade ao jornalista para exprimir suas opiniões em sua célebre e premiada coluna "Today and Tomorrow".

3 É o que se observa, por exemplo, em Drift and mastery, em que Lippmann afirma que a ciência não deve restringir-se a uma elite dirigente, mas voltar-se à cooperação coletiva, deliberativa e democrática. Tal concepção antipositivista e democrática de ciência associada à experimentação coletiva destoa da concepção elitista de "governo de experts", predominante no pensamento de Lippmann (Stiegler, 2019, p. 42-43). Desse modo, a autora acaba por sublinhar também a incompatibilidade existente na obra de Lippmann entre, de um lado, a influência pragmatista, que acentua experiências sociais horizontais com base no pressuposto potencial de cada indivíduo, e, de outro, a concepção verticalizada de poder segundo a qual uma elite dirigente conduz, a partir do conhecimento científico especializado, a massa informe e incompetente para questões públicas (p. 32, 36-37). 
virtude, precisamente, de princípios democráticos e liberais - e da Grande Depressão (1929). Em comum, além do contexto, está o recurso de ambos à teoria da evolução darwinista para refundar o naturalismo liberal. Suas apropriações, porém, são diversas: de um lado, Lippmann defenderá a adaptação passiva da espécie - caracterizada pela lentidão evolutiva - ao ambiente industrializado e mundial extremamente veloz a partir de uma concepção elitista de poder e, de outro, Dewey sustentará uma interação ativa e complexa entre o meio e a espécie, incorporando positivamente suas diferenças de ritmos evolutivos como forma de desenvolvimento social, cultural, cognitivo e político e concebendo a democracia como experiência coletiva e forma de vida comum. Desse modo, utilizandose constantemente de antagonismos, a professora de filosofia política da Universidade de Bordeaux traz a público, em seu livro, as questões que constituíram o Lippmann-Dewey Debate, assim nomeado desde a publicação de Communication as culture, de James Carey, em 1989, mas cuja discussão remonta efetivamente aos anos 1920 - ao pré-neoliberalismo, portanto. ${ }^{4}$

É verdade que o jornalista, ensaísta e diplomata norte-americano sairá, podemos dizer hoje, retrospectivamente, "vitorioso" de tal embate, considerando sua influência posterior tanto na formação das elites no plano mundial quanto na formulação teórica e política do neoliberalismo - o

${ }^{4} \mathrm{~A}$ autora assinala as repercussões das controvérsias em torno do Lippmann-Dewey Debate, mapeando trabalhos que confirmam sua existência e os que a detraem (p. 96-99). No interior dessa polêmica, desdobra-se outra, relativa ao pertencimento de Lippmann à tradição pragmatista. Tal é a posição, por exemplo, de Bruno Latour (2008), que, embora não negue a existência do debate, sustenta sua existência no interior do pragmatismo, conferindo a Lippmann, assim, os atributos de um verdadeiro democrata. Posição da qual Stiegler (p. 303, nota 9 , e p. 306, nota 56) discorda veementemente. Para a autora, a oposição fundamental de Dewey em relação a Lippmann repousa na apropriação diversa do evolucionismo darwiniano, cujas implicações são concepções radicalmente distintas de democracia (participativa/representativa) e de poder (horizontal-experimental/vertical-elitista). Registrese também as particularidades interpretativas conferidas ao termo "ajustement". Para Latour (2008, p. 17), trata-se de reter sua raiz "juste", de que se depreendem noções de justiça e equidade. Com efeito, como mostra Stiegler (p. 209-217, 259), a questão de Lippmann consiste em tornar a competição justa, em termos de "igualdade de chances". Porém, a autora assinala que o estabelecimento das "regras do jogo" ("the rules of the game" e "fair play") para tanto tem como finalidade fazer vencer os melhores e mais aptos. Em outras palavras, significa dizer que "ajustement" remete à noção de "adaptação" à competição desenfreada, cujo efeito é a produção de desigualdades e injustiças sociais, o que a evidenciação histórica do neoliberalismo ratifica. 
Colóquio Walter Lippmann (1938), vale lembrar, ocorre por ocasião do lançamento de La cité libre, tradução francesa de The good society realizada um ano após sua publicação original. O pragmatismo de John Dewey, por outro lado, constituirá a primeira crítica filosófica do neoliberalismo, antes mesmo de sua constituição efetiva, isto é, em seu momento germinal. Tal é a tese que Barbara Stiegler sustenta em seu livro, observando que a questão passara ao largo, até então, não apenas do autor de Nascimento da biopolítica, mas também de quase todos os pesquisadores que se inscrevem na tradição dos estudos foucaultianos do tema. A única exceção - assinala Stiegler em uma nota de rodapé - é A nova razão do mundo, obra já clássica sobre a sociedade neoliberal, em que Pierre Dardot e Christian Laval capturam, ainda que sem recorrer às fontes evolucionistas, a noção-chave da produção lippmanniana, como se lê na passagem a seguir: "A palavra importante na reflexão de Lippmann é adaptação. A agenda do neoliberalismo é orientada pela necessidade de uma adaptação permanente dos homens e das instituições a uma ordem econômica intrinsecamente variável, baseada em uma concorrência generalizada e sem trégua" (Dardot; Laval, 2016, p. 89-90 [trad. modificada, grifos no original] apud Stiegler, 2019, p. 322). Sua genealogia, informa-nos Stiegler (p. 322, nota 4), provém dessa observação incidental, da qual sobressaem, contudo, as ideias centrais de I/ faut s'adapter. ${ }^{5}$

Com efeito, procurando analisar o uso do vocabulário biológico do evolucionismo no campo político, a questão fundamental do livro consiste em problematizar o suposto atraso da espécie humana em relação ao

${ }^{5}$ No capítulo dedicado ao Colóquio Walter Lippmann, Dardot e Laval (2016, p. 71-100) abordam os temas centrais da obra de Lippmann, especialmente de La cité libre, tais como as noções de "intervencionismo (neo)liberal" em contraposição ao laissez-faire do liberalismo clássico; de interdependência e da divisão mundial do trabalho na Grande Sociedade; da adaptação à competição; do papel da educação para a especialização e da eugenia para o aperfeiçoamento genético; e do governo de elites. Assim, os autores também destacam que a ideia de adaptação é central em uma sociedade que estabelece a competição como princípio vital. Observe-se, por exemplo, a afirmação deles a respeito da função do intervencionismo neoliberal: "Ele visa, em primeiro lugar, a criar situações de concorrência que supostamente privilegiam os mais 'aptos' e os mais fortes e a adaptar os indivíduos à competição, considerada a fonte de todos os benefícios [grifo nosso]" (Dardot, Laval, 2016, p. 288). O problema contemporâneo, sustentam os autores, consiste na adaptação subjetiva à intensificação da competição tornada absoluta. Stiegler avança em seu estudo ao investigar a proveniência do problema a partir de bases naturalistas e evolucionistas. 
ambiente industrial da "grande sociedade", ${ }^{6}$ cujas características são a abertura, a contingência, a complexidade, a competição e a velocidade. Para Lippmann, como vimos, trata-se de fazer o homem adaptar-se a um ambiente em constante evolução. Os métodos para tanto envolvem uma concepção minimalista e procedimental de democracia, em que uma elite de dirigentes eleitos e de especialistas não eleitos conforma e comanda a massa considerada estática, passiva e inepta. Segundo tal concepção de poder, que podemos compreender também como positivista, deve-se impor o modelo de vida social condizente com o desenvolvimento histórico evolutivo desde cima, a partir da elite. ${ }^{7}$ Totalmente contrária ao pensamento político de Dewey, uma das marcas da obra lippmanniana destacadas no livro de Stiegler reside, precisamente, na desconsideração da inteligência coletiva, da participação e da opinião públicas; a consulta ao público, em sua integralidade, deve restringir-se pontualmente às eleições, ou a momentos de crise, em que o povo constitui o último recurso de governo. A razão elementar para o autor de Public opinion e The phantom public é que o público seria sempre incompetente para tratar de questões de que não possui discernimento em uma sociedade altamente especializada. ${ }^{8}$

Em seu conjunto, a espécie humana é percebida por Lippmann como atrasada. $\mathrm{O}$ atraso, aqui, diferentemente de Dewey, tem conotação

${ }^{6} \mathrm{O}$ termo "grande sociedade", que se encontra também na obra de Dewey, provém do socialista inglês Graham Wallas (1858-1932), mentor e amigo de Lippmann que escreveu The great society: a psychological analysis (1914). O termo remete diretamente à ideia de mundialização e globalização decorrentes das revoluções industriais (Stiegler, 2019, p. 3841; Latour, 2008, p. 183, nota 3).

7 De acordo com Stiegler (p. 73), em Public opinion, Lippmann exalta o papel do cientista político Charles Merriam e do industrial Frederick Taylor na qualidade de especialistas que conduzem o processo de readaptação da espécie e de governo da população. Temos aí a ideia de exercício do governo a partir de uma elite da humanidade formada por cientistas e industriais, o que nos remete às noções do positivismo comteano de "poder espiritual" e "poder temporal" (Aron, 2008, p. 83-183).

${ }^{8} \mathrm{~A}$ ideia fundamental é que os indivíduos seriam competentes em suas questões e alheios a todo o restante. É desse modo que Bruno Latour (2008) defende o argumento segundo o qual Lippmann é um verdadeiro democrata, na medida em que subtrai as ilusổes da democracia (o público fantasmático, unívoco, do bem e da vontade geral e comum) para afirmá-la em sua efetividade histórica, uma vez que não é mais possível atuar na grande sociedade mundializada conforme o modo idealizado da pólis grega. Daí a afirmação de que Lippmann é provavelmente o único pensador político a laicizar efetivamente a democracia - isto é, a subtrair suas características metafísicas idealizadas -, e a considerar de maneira positiva a desmobilização do público, para cada um voltar-se a suas ocupações específicas. Como vimos, Stiegler opõe-se a tal leitura (cf. nota 4). 
exclusivamente negativa, é uma forma de desqualificar a natureza humana, como se ela não estivesse à altura da época industrial. A questão, para o autor, resume-se em superar e eliminar a contradição existente entre a espécie (estável e limitada) e o ambiente (fluido e ilimitado). Sua ênfase repousará na necessidade de moldar e normalizar a espécie passiva a partir da dimensão ativa e nobre da grande sociedade industrial. Daí a noção de uma "biopolítica disciplinar lippmanniana": partindo do pressuposto da deficiência da natureza humana em relação ao meio, trata-se de impor à massa dispositivos de normalização de hábitos e de disposições psicológicas mediante investimentos em políticas públicas (educação, saúde, meio ambiente) para fazer funcionar um governo cujo objetivo é aprimorar a vida e as capacidades humanas. A metáfora da qual a autora lança mão para elucidar o procedimento é a de "pâte molle" (massa mole): conceber os indivíduos como absolutamente flexíveis e cada vez mais adaptáveis à aceleração do mundo contemporâneo, cujo fim é, tal qual a evolução teleológica de Spencer, a divisão mundial do trabalho, a cooperação competitiva e a competição cooperativa em uma economia capitalista mundializada. ${ }^{9}$ Se o século de Adam Smith requeria do indivíduo a especialização única, a grande sociedade do século XX requer a adaptabilidade, a partir da qual indivíduos flexíveis e com especialidades múltiplas podem migrar para situações sempre novas. Eis os objetivos educacionais da agenda neoliberal depreendidos desde Lippmann: preparar a flexibilidade, a adaptabilidade e empregabilidade

9 Como mostra Stiegler, Lippmann se distancia, contudo, da "fobia de Estado" spenceriana, dado que a refundação do liberalismo se assenta, como vimos, no princípio da intervenção estatal para fazer funcionar a economia de mercado. Lippmann afasta-se, assim, da crença spenceriana na evolução mecânica e natural, que dispensa a elaboração de políticas para sua realização. Sobre a importação das ideias de Spencer nos EUA no início do século XX, após seu declínio na Europa, especialmente na Inglaterra, e a necessidade de refundar o evolucionismo no campo político, ver a seção "La cible spencérienne" (Stiegler, 2019, p. 22-28). 
dos indivíduos. ${ }^{10}$ Em outros termos, valendo-se do léxico biológico darwinista, trata-se de fazer a espécie humana adaptar-se ao fluxo ilimitado e extremamente veloz dos acontecimentos e da produtividade impostos brutalmente pela sociedade industrial, que constitui, para Lippmann, a "grande revolução". ${ }^{11}$ Temos aí uma das proveniências da noção, cada vez mais potencializada, de adaptação a um ambiente que requer a ilimitação das capacidades humanas. ${ }^{12} \mathrm{O}$ mérito de Stiegler está em mostrar como não estamos aqui no campo de uma teoria econômica abstrata como a da escolha racional, mas em uma elaboração teórica que envolve uma concepção específica de vida e de evolução. Trata-se do coração teórico do neoliberalismo, sua matriz política, sociológica e antropológica.

É verdade que Dewey pretende, da mesma forma, refundar o liberalismo com princípios antiestatizantes e naturalistas, a partir também

\footnotetext{
${ }^{10}$ Em diversos momentos do livro, Stiegler retoma a discussão em torno da ideia de "agenda neoliberal", para distinguir da "não agenda" do laissez-faire, em que repousa, novamente, a diferença entre Lippmann e Spencer. Retomando a etimologia latina da palavra, em que agere designa fazer, trata-se de estabelecer, assim, uma diferença de concepção da natureza humana entre a refundação do liberalismo proposta por Lippmann e o liberalismo clássico. Enquanto este concebe a natureza humana como "boa", razão pela qual se dispensa toda forma de intervenção, o pressuposto elementar de Lippmann reside na deficiência da natureza humana. Daí a afirmação de Stiegler (p. 228) de que a biopolítica lippmanniana reativa o "fundamento antropológico da disciplina", cuja finalidade é adaptar e normalizar a espécie conforme os imperativos da grande sociedade. A agenda neoliberal nascente repousa essencialmente em políticas de educação, saúde e meio ambiente. Dardot e Laval (2016, p. 58-60, 69, 273, 278) também realizam tal discussão a partir do "novo liberalismo" de Keynes e em relação ao Estado gerencial contemporâneo. As noções de "agenda" e "não agenda" também são mencionadas por Foucault (2004b, p. 13-14, 27, 139, 200) ao referirse a Bentham e ao novo "estilo de governar" do neoliberalismo.

11 Enquanto a "grande revolução" é compreendida por Lippmann a partir da divisão mundial do trabalho e da interdependência instauradas pela revolução industrial, Dewey a reconhece, antes, na revolução científica e técnica do século XVII, atribuindo, assim, centralidade à experimentação e à inteligência coletivas, que fundamentam sua concepção própria de democracia. Ver especialmente capítulo V "La grande révolution : mettre la I'intelligence hors de circuit" (Stiegler, 2019, p. 159-187).

12 Para analisar a ideia de ilimitação das capacidades humanas como efeito da racionalidade neoliberal nos dias atuais, Dardot e Laval (2016, p. 357) criaram o termo "ultrassubjetivação", cuja definição básica consiste em uma constante superação de si (o além de si em si). A esse respeito, ver também Laval (2020) e Corbanezi; Rasia (2020).
} 
da importação da teoria da evolução darwiniana para o campo político. Mas suas concepções são, de maneira geral, diametralmente opostas às de Lippmann. Se, para este, a heterocronia dos ritmos evolutivos (espécie e meio) é percebida como "discronia" - isto é, desajustamento e disfunção -, cuja solução compete ao governo da elite dirigente baseada no conhecimento de especialistas, para Dewey, ao contrário, trata-se de afirmar a heterocronia não como problema, mas como condição necessária para o desenvolvimento das potencialidades de que todos os indivíduos são portadores. Desse modo, em vez de um público inepto submetido à adaptação passiva, Dewey pressupõe a evolução a partir de interações ativas e complexas, considerando irredutíveis as diferenças de ritmos entre organismo e meio e entre os próprios indivíduos. Especialista também em Nietzsche, Stiegler (p. 127, e 307-308, nota 71) sustenta que Dewey afirma tragicamente tanto o atraso, como força ameaçadora e necessária, quanto a tensão constitutiva entre fluxo e estabilidade. Trata-se de perceber a evolução a partir das potencialidades e diferenças dos indivíduos, não os reduzindo ao postulado da deficiência antropológica da espécie. Stiegler mostra, nesse sentido, as críticas contundentes de Dewey ao indivíduo "médio" e "modulável" de Lippmann. Considerando as potencialidades dos indivíduos, o autor de The public and its problems (1927) fundamenta a necessidade de participação direta do público no governo, a partir da inteligência coletiva e da constante experimentação social. Desse modo, a democracia é concebida por Dewey como forma de vida, para além do aspecto meramente institucional, procedimental. Seu problema, sustenta o autor de Democracy and education (1916), não é a suposta incompetência cognitiva da massa, tal como postula Lippmann, mas a concentração de riquezas materiais, cognitivas, culturais e espirituais nas mão de uma elite restrita. Daí o papel fundamental da educação para este autor que influenciou, no Brasil, de Anísio Teixeira a Paulo Freire: a socialização da inteligência, a distribuição de saber e cultura como forma de realização da democracia e da justiça social. Se, para Lippmann, o devir evolutivo é comandado pela elite em direção a um télos estabelecido e transcendental (a divisão mundial do 
trabalho em uma economia globalizada), para o pragmatismo deweyano a evolução se dá mediante processos e experimentações imanentes e abertos, isto é, sem o primado da finalidade, confiante nas potencialidades e singularidades individuais que resultam de interações múltiplas. Autor fundamental para a tradição sociológica microinteracionista (Collins, 2009, p. 205-243), Dewey postula que a redução da complexidade interativa ao domínio econômico, assim como do trabalho ao lucro e à competitividade, mina a reserva inesgotável de potencialidades individuais. Criticando a "desindividuação", isto é, a padronização das maneiras de sentir e pensar provocadas pela concepção liberal de indivíduo atomizado, Dewey quer saber como de arranjos interativos imprevisíveis e de processos coletivos de individuação emergem singularidades irredutíveis. ${ }^{13}$ É desse modo que Stiegler, fazendo notar sua predileção pelo pensamento de Dewey, sustenta que o pragmatismo deste, ainda que pretendendo refundar o liberalismo com premissas evolucionistas, constitui a primeira crítica filosófica e política do neoliberalismo vindouro.

É o sentimento difuso e permanente de atraso que motiva a genealogia de Stiegler. Trata-se do problema moderno da relação entre aceleração e adaptação, já diagnosticado desde Hegel, Marx e Nietzsche. "Todo atraso é, em si mesmo, uma desqualificação?", questiona-se a autora. E prossegue, sem deixar de distinguir a oposição entre Lippmann e Dewey: "É preciso desejar que todos os ritmos se ajustem e se alinhem com uma reforma gradual da espécie humana que iria no sentido de sua aceleração? Não seria necessário, ao contrário, respeitar as irredutíveis diferenças de ritmos que estruturam toda história evolutiva?" (p. 18). Sabemos em que direção "evoluíram" historicamente os processos de neoliberalização das sociedades. A pandemia de Covid-19 - que atravessou os anos de 2020 e de 2021 - suscitou, em certos meios, a discussão em torno de um "novo normal". Ora, a emergência de um "novo normal" implicaria a ruptura com um normal precedente. Se consideramos que o mundo moderno se

${ }^{13}$ Nesse sentido, parece-nos que seria pertinente investigar as possíveis relações entre as premissas interativas de Dewey e as noções de potenciais da realidade pré-individual, de individuação e de acoplamento indivíduo-meio elaboradas por Gilbert Simondon (2005). 
caracteriza, estruturalmente, pela velocidade, controle, monetarização, instabilidade, sacralização do trabalho, da produtividade e do lucro, o que assistimos, após uma parada mundial momentânea, é o retorno, em velocidade aceleradíssima, de processos e tendências em curso desde o início da modernidade. A polivalência, a hiperatividade (atualmente digital e sobretudo mental), a flexibilidade, a adaptabilidade - atributos necessários para a reinvenção do liberalismo nos anos 1930 - são ingredientes mais do que nunca indispensáveis à sobrevivência. Experimentamos, hoje, a potencialização do já velho normal ao qual a espécie - e não menos o meio, considerando um modo de produção extrativista e predatório - procuram adaptar-se há séculos. ${ }^{14}$

A nosso ver, portanto, o livro de Barbara Stiegler se apresenta como uma pesquisa relevante sobre a genealogia do neoliberalismo, elaborada na esteira dos estudos foucaultianos, ainda que a autora afirme, circunstancialmente, em nota de rodapé, que o silêncio de Foucault a respeito dos aspectos disciplinares da biopolítica neoliberal tenha dado margem para as controvérsias em torno da interpretação de sua aliança "real" ou "suposta" com o neoliberalismo (p. 317, nota 17). Embora a autora se distancie inequivocamente de tal posição, concordamos com Christian Laval (2018, p. 21), que refuta em absoluto tal hipótese interpretativa:

Considerar Foucault como um autor neoliberal só é possível ao preço de um desconhecimento de seu trabalho genealógico sobre os poderes e seu engajamento ético e político. A história intelectual é, aliás, repleta desses contrassensos que fazem de Marx o inventor do Gulag ou de Nietzsche um autor nazista. ${ }^{15}$

\footnotetext{
${ }^{14}$ Em outros termos, significa dizer que assistimos, atualmente, à aceleração de um processo cujo início é a modernidade: podem-se alterar as formas, mas os princípios permanecem (trabalho, lucro, produtividade, velocidade etc.). Ao afirmarmos que não há propriamente ruptura entre modernidade e contemporaneidade, mas transformações, acentuações, deslocamentos, distanciamo-nos de polêmicas, muitas vezes equivocadas, em torno da pósmodernidade. O que presenciamos é a radicalização da modernidade - eis o diagnóstico de autores contemporâneos tão diversos como Anthony Giddens, Michel Foucault e Zygmunt Bauman, entre outros.

${ }^{15}$ A esse respeito, ver Corbanezi (2014), em que procuramos criticar a leitura neoliberal que Geoffroy de Lagasnerie apresenta de Foucault.
} 
Stiegler antecipa também possíveis objeções ao seu livro, como, por exemplo, a exigência de se reavaliar a centralidade do pensamento de Lippmann nas diferentes correntes que constituem o neoliberalismo, bem como o não aprofundamento do estudo a respeito do impacto atual da discussão sobre a tradição lippmanniana e pragmatista em campos específicos, como educação, saúde e ambiente. De todo modo, ao realizar uma pesquisa de fôlego sobre a genealogia crítica das fontes evolucionistas do neoliberalismo, a autora apresenta uma contribuição significativa tanto ao público interessado em compreender a proveniência da atual forma de governo de nossas condutas cotidianas quanto à démarche foucaultiana, segundo a qual o dado biológico possui sempre valor político. E não é diferente no neoliberalismo, desde suas origens.

Elton Corbanezi é Doutor em Sociologia e professor do Departamento de Sociologia e Ciência Política e do PPGS da Universidade Federal de Mato Grosso.

$\triangle$ eltonrcorbanezi@gmail.com

\section{Referências}

1. ARON, Raymond. As etapas do pensamento sociológico. Trad. Sérgio Bath. São Paulo: Martins Fontes, 2008. (Coleção tópicos).

2. COLLINS, Randall. Quatro tradições sociológicas. Trad. Raquel Weiss. Petrópolis: Ed. Vozes, 2009. (Coleção Şociologia).

3. CORBANEZI, Elton; RASIA, José Miguel. Apresentação do Dossiê: racionalidade neoliberal e processos de subjetivação contemporâneos. Mediações - Revista de Ciências Sociais, v. 25, n. 2, p. 287-301, 2020.

4. CORBANEZI, Elton. Geoffroy de Lagasnerie: uma polêmica leitura neoliberal de Foucault. Revista Brasileira de Ciências Sociais, v. 29, n. 84, p. 195-199, 2014.

5. DARDOT, Pierre; LAVAL, Christian. A nova razão do mundo: ensaio sobre a sociedade neoliberal. Trad. Mariana Echalar. São Paulo: Boitempo, 2016. (Coleção Estado de Sítio).

6. FOUCAULT, Michel. Sécurité, territoire, population : Cours au Collège de France (1977-1978). Paris: Seuil /Gallimard, 2004a.

7. FOUCAULT, Michel. Naissance de la biopolitique : Cours au Collège de France (1978-1979). Paris: Seuil /Gallimard, $2004 b$. 
8. LATOUR. Bruno. Le fantôme de l'esprit public. Des illusions de la démocratie aux réalités de ses apparitions. In: LIPPMANN, Walter. Le Public Fantôme. Paris: Démopolis, 2008. p. 3-44.

9. LAVAL, Christian. A pandemia de Covid-19 e a falência dos imaginários dominantes. Trad. Elton Corbanezi. Mediações - Revista de Ciências Sociais, v. 25, n. 2, p. 277-286, mai/ago. 2020. http://dx.doi.org/10.5433/2176$\underline{6665.2020 v 25 \mathrm{n} 2 \mathrm{p} 277}$

10. LAVAL, Christian. Foucault, Bourdieu et la question néolibérale. Paris: La Découvert, 2018.

11. SIMONDON, Gilbert. L'individuation à la lumière des notions de forme et d'information. Grenoble: Millon, 2005.

12. STEEL, Ronald. Walter Lippmann and the American Century. New Brunswick: Transaction Publishers, 1999.

13. STIEGLER, Barbara. II faut s'adapter : sur un nouvel impératif politique. Paris: Gallimard, 2019. 
